\title{
Reflecting back to move forward with suicide behavior estimation for First Nations in Canada
}

\author{
Brenda Elias \\ Community Health Sciences, University of Manitoba, Winnipeg, MB, Canada \\ E-mail: brenda.elias@umanitoba.ca
}

\begin{abstract}
While many countries produce suicide rates, within country estimation practices may privilege the dominant society and fail to report suicide estimates for populations historically discriminated against. In Canada, national suicide mortality studies are rarely reported for Indigenous populations. Yet, this population is known for high suicide behavior. Administrative, census and survey data are available but are not systematically or critically analyzed. To address this gap, this paper provides an overview of social-political drivers to improve Indigenous statistics (particularly for suicide) and opportunities to report Indigenous suicide via different data sources in Canada. A case study illustrates the use of multiple data sources to report suicide and its correlates for an Indigenous group residing in the Province of Manitoba (Canada). Recommendations then follow to improve Indigenous statistics for suicide.
\end{abstract}

Keywords: Indigenous, suicide, administrative data, survey data, United Nations, Canada's Truth and Reconciliation Commission

\section{Introduction}

The International Group for Indigenous Health Measurement (IGIHM), founded in 2005, has collaborated to promote and improve the availability, accessibility, quality, depth and utility of data, including innovative techniques to improve mortality, morbidity and health determinant measures for Indigenous populations throughout the world [1]. In the fall of 2017, the working group advanced the need to greatly increase the reporting of suicide amongst Indigenous populations. Supporting this decision is a recent systematic review that reported elevated suicide incident rates amongst many Indigenous populations globally, with rate variation common across and within regions [2]. Studies conducted in high-income countries like Canada, United States, Australia and New Zealand have shown higher suicide rates amongst Indigenous populations [3,4]. The suicide rate for First Nations in the Atlantic and Western Canada region for the period 2003-2007 was 30.4 deaths per 100,000 (95 percent CI: 23.7-37.0), which was three times higher than the Canadian population [5]. In the United States, suicide rates were 50 percent higher among American Indians and Alaska Natives (21.2), when compared to Whites (14.2), with rates highest in Alaska and the Northern Plains [6]. In Australia between 1994 and 2007, Indigenous populations in Queensland had a suicide rate that was 2.2 times higher than non-Indigenous Australians [7]. In the Kimberley region for the period 2005-2014, where suicide historically was nonexistent amongst Indigenous peoples, the Indigenous suicide rate was significantly higher at 74 per 100,000 as opposed to 10 per 100,000 for the non-Indigenous population [8,9]. In New Zealand, the Maori suicide rate was higher than non-Maori for the period 1996 to 1998, then rates converged in 1999 but increased for Maori in 2002 [10]. A similar pattern was shown for Indigenous Australians [11,12].

Overall, these studies demonstrate the value of producing Indigenous statistics for suicide. That being said, the reporting of Indigenous statistics, including for suicide, has been inconsistent in Canada [13,14] and internationally [15], with minimal and infrequent 
measurement of mental health and wellness [16]. This paper addresses this reporting disparity. First by highlighting important social-political drivers to improve Indigenous statistics, followed by an examination of potential administrative and survey data sources for reporting Indigenous suicide in Canada. Following this discussion is a case study of a research program that accessed multiple data sources and utilized different ways to report suicide rates, including the social-historical-contemporary drivers of suicide for one Canadian Indigenous group residing in the Province of Manitoba (Canada).

\section{Catalysts for improved indigenous statistics in Canada}

Since 2005, Canadian and international IGIHM members have collaborated to promote and improve Indigenous statistics [1,13-16]. Within Canada, another significant and recent catalyst has been Canada's Truth and Reconciliation Commission (TRC) on the Indian Residential School System [17]. This national commission evolved from the Indian Residential Schools Settlement Agreement to settle a class action suit of residential school survivors. The TRC examined the state and church-operated school system that sought to remove the Indian from the child and integrate that child into a settler society. The TRC documented the impacts told by Indigenous peoples who were taken from their families and placed in residential schools for most of their childhood. The commission concluded that over 100 years the residential school system endangered the health and wellbeing of children who attended the schools. This impact, when added to other colonial policies, eroded the intergenerational health of Indigenous peoples thereafter. In its 2015 Call to Action, the TRC recommended the establishment of measurable goals for identifying and closing the gaps in health outcomes, including suicide for Canada's Indigenous populations.

Another potential international catalyst for improved Indigenous statistics is the United Nations (UN) 2030 Sustainable Development Goals (SDG) [18]. Goal SDG3, for instance, aims to ensure healthy lives and promote well-being for all at all ages, and via target SDG3.4 reduce by 2030 one third of premature mortality from non-communicable diseases by way of prevention, treatment and the promotion of mental health and well-being. Listed within target SDG3.4.2 is the suicide rate. In accordance with the UN Fundamental
Principles of Official Statistics, all indicators including suicide rates should be disaggregated where possible by income, sex, age, race, ethnicity, migratory status, disability, geographic location, or other characteristics. The UN Statistical Commission [19] further noted that additional indicators could also be reported. While theoretically laudable, actionable measurement and reporting for Indigenous populations has been lacking. UN statistical structures, for example, have lagged in responding to the UN Declaration of Indigenous Peoples and the increased calls for improved Indigenous statistics [20]. The UN Permanent Forum on Indigenous Peoples, in response to the SDGs, has recently contended that the SDG indicators are only a practical starting point to evolve indicators relevant to Indigenous peoples in local contexts [21]. In Canada, by illustration, the Assembly of First Nations, which is a national First Nations political organization, had recommended that the Federal-Provincial-Territorial governments work with First Nations, locally and nationally, to develop common and locally relevant indicators for critical areas such as mental health and wellness [22]. To support the development of a set of indicators, it is also important to consider the data sources from which to draw or develop indicators.

\section{Canadian suicide data sources}

In Canada, a key source of suicide data is provincially recorded vital events that are reported to Canada's national vital statistics system [23-25]. Statistics Canada collects demographic and cause of death information annually from all provincial and territorial vital statistics registries on all deaths. Cause of death is classified according to the World Health Organization (WHO) International Statistical Classification of Diseases and Related Health Problems (ICD) by revision version and year of data (e.g., from ICD-3 19211931 to ICD-10 2000 to present) [26]. From this data, Statistics Canada has showed that the national suicide rate in 2009 was 11.5 per 100,000 , which was ranked ninth leading cause of death, and seventh leading cause for males and thirteenth leading cause for females [27]. Although the highest rates occurred in the age groups 40-59 (both sexes), suicide was the second leading cause of death for those aged 15 to 34 years. Since then, the suicide rate for all ages has incrementally increased from the lower 11.3 rate per 100,000 reported in 2011 to the higher 12.3 rate per 100,000 reported for 2015 [24]. While this report shows a robustness in re- 
porting, suicide rates were not comparatively reported for First Nations, Métis and Inuit due to a lack of an Indigenous identifier in the vital statistics data system. To address this gap, the following data approaches have evolved to produce Indigenous suicide statistics.

The federal Health Canada regional First Nations and Inuit Health Branch have used multiple data sources to estimate self-harm. For the period of 2003 2007, the department produced First Nation death data based on the usual residence of the deceased (numerators), which was only available departmentally for Western Canada [5]. To compare First Nations to the general population, non-Indigenous mortality data were drawn from Statistics Canada Vital Statistics databases. First Nation denominators were obtained from the Indian Register held by the federal department of Indigenous Affairs. These denominators were adjusted for late and under-reporting of deaths on adjusted 2009 counts. Population estimates for the general population were obtained from the 2006 Canadian Census of the Population. For the 2003-2007 period, the Western Canada First Nations suicide rate, previously noted, was three times higher than the agestandardized general population rate $(30.4$ per 100,000 at 95 percent CI: 23.7-37.0). The largest portion of deaths occurred among First Nations aged 10 to 24 years (28.9 percent $10-14$ years, 30.1 percent 15 18 years, 23.6 percent $20-24$ years, 13.4 percent $25-$ 44 years). The rate for First Nation males were two times higher (39.3 deaths per 100,000, 95 percent CI: 28.7-49.9) than the First Nation female rate (21.2 deaths per 100,000, 95 percent CI: 13.3-29.2). As in other populations, these estimates should be viewed as conservative due to the nature of health authority reporting, the way suicide is classified in death records, the time lag in determining suicide as a cause of death [28-30], and the way Indigenous peoples are identified in these databases [13,31]. Since this report, no other national report has been published by the Canadian federal government on Indigenous suicide mortality.

To overcome the lack of line-level ethnicity identifiers in administrative databases, Statistics Canada census data has been used to identify sub-regions that proportionally have a high number of Indigenous people residing [32]. In a recent study, the Statistics Canada's Vital Statistics death database was disaggregated by region of residence to account for suicide mortality in the province of Labrador-Newfoundland [33]. Statistics Canada's census division geographic units were used to group regional populations and then sub-regional populations by combining smaller units (census subdivisions) that were approximately equivalent to communities. Sub-regional groupings of predominantly Indigenous communities were then used as a proxy measure for Innu communities, Inuit communities and southern Inuit communities. By using geo-coding, the suicide rate was found to be four times higher in Labrador than in Newfoundland, and that sub-regions predominated by Labrador Innu and Inuit communities had the highest age-standardized suicide rates respectfully at 165.6 and 114.0 per 100,000 person-years. Overall, this study demonstrated the value of building proxy geo-Indigenous measures. Unfortunately, these measures cannot infer individual risk without line level ethnicity identifiers.

Another source of national suicide data is the Canadian Institute for Health Information's national hospital discharge abstract database (DAD) for nine provinces (excluding Quebec) and the three northern territories (Yukon, NWT and Nunavut). A study linking census data to the hospital discharge abstract data from 2006/2007 through 2008/2009 generated a possible solution to the lack of ethnicity identifiers in this database [34]. Although this study was not directed at suicide, it showed a potential technique to report on a suicide that resulted in an acute care hospital visit. In this study, the 2006 Census data was linked to hospital administrative data for the purpose of reporting acute care hospitalizations for First Nations living on and off reserve, Métis, and Inuit for all of Canada, except Quebec. A hierarchical deterministic linkage, previously validated, was conducted using date of birth, sex and residential postal code. Indigenous identity, which was reported on the census (First Nations living on and off reserve, Métis and Inuit), was used for disaggregation purposes. From this linkage, the analysis showed that mental and behavioral disorders frequently resulted in a hospitalization for Indigenous Canadians far more than non-Indigenous Canadians. While this approach has value, a major limitation was the lower rate of census coverage for Indigenous peoples, with some groups resisting participation or selfidentifying as Indigenous. Consequently, Indigenous under-representation is a possibility, which may result in a downward estimate bias when compared to estimates produced for non-Indigenous peoples.

Another source of suicide data is provincial medical examiner (coroner) reports that inform vital statistics records. These data tend to have more accurate suicide completion counts, providing that the death was self-inflicted with the intent to die. Not all suicides, 
however, are captured which consequently impacts vital event counts. The examiner, for instance, may miss impulsive suicides, which are miscoded as undetermined or accidental $[3,30]$. Another bias, as illustrated in the coroner suicide studies from the Province of Manitoba (Canada), was the way the medical examiner documented Indigenous suicides [35-37]. If the examiner's report did not include an Indigenous identifier, there was no way to group these deaths. If a pan-Aboriginal identity question was used (Aboriginal yes or no), this grouping identifier may have little relevance to federally funded First Nations [38] onreserve suicide prevention initiatives. If the reporting form includes any type of Aboriginal ethnicity field but the kin are unknown, the examiner may not reliably determine ethnicity. If the examiner chooses not to record ethnicity, file reviewers may construct the deceased's ethnicity by using the deceased's postal code to ascertain residency in a First Nation on-reserve community. Another approach is constructing an identity from the examiner's notes on physical features that may suggest Indigenous ethnicity. All approaches, regardless, can result in a misclassification bias. To calculate rates from these data, population denominator data is required. Potential denominator data includes Statistics Canada's Census data grouped using selfidentity questions, the Indian Registry System (IRS) and Health Canada's Status Verification System (SVS) for the on-reserve population, which is derived from the IRS [39]. All three sources have limitations. Statistics Canada Census ethnicity data is prone to selfidentification bias. The IRS or SVS data are limited by legal restrictions on who can register as an Indian (registered First Nations) and by inaccurate or missing residency counts for the on and off reserve populations [13,39].

Another source of suicide data is population surveys that collect information on the prevalence of suicide thoughts and attempts. In Canada, unfortunately, there is not one source of survey data for Canada's Indigenous population but several. For the general population, a key national source is the Canadian Community Health Survey that gathers health related data at sub-provincial geographic levels [40]. This survey, however, excludes First Nations on-reserve and Indigenous peoples in small settlements, including Quebec's Indigenous population. By excluding high-density Indigenous areas, the Indigenous people sample at the health authority level is prone to data suppression rules. Another survey undertaken by Statistics Canada is the Aboriginal Peoples Survey (APS) of Métis, Inuit and First Nations living off-reserve [41]. Data from 2012 showed that nearly a quarter of First Nations living off reserve (24 percent) and Inuit (23.5 percent), followed by 19.6 percent of Métis, had suicidal thoughts over their lifetime, and Indigenous young adults were two times greater than non-Indigenous young adults to have lifetime suicidality [42]. For all three groups, the correlates of suicide thoughts were mood and/or anxiety disorder, ever using drugs, or hopelessness as opposed to high self-worth which was protective. Unfortunately, this survey excludes the First Nation on-reserve population, which is worrisome for regions like Manitoba, where suicide rates have been higher among the on-reserve population [36]. As well, only a minimal set of social determinant data is collected, and a major measurement gap are the colonial, historical and other life stressors associated with suicide.

The First Nations Regional Health Survey (RHS), launched in 1997 and under the governance of First Nations, is the only national source of First Nation on-reserve data in Canada. For the period 2009 to 2010, it was found that 22 percent of the on-reserve First Nation adult population had lifetime suicide thoughts [43]. A major strength of this survey is that it includes relevant social determinant questions on western and Indigenous understandings of health and well-being, including intergenerational colonial impacts (residential school). While the dataset includes a regional identifier, the data unfortunately cannot be readily disaggregated by regions out of respect for regional First Nation governance structures. Access to regional data occurs at that level only. Consequently, a national-regional comparative picture of suicide behaviors may not occur. A shared weakness across both surveys is that the outcome measure, suicide thoughts or attempts, may be under-reported due to recall bias and selection bias (e.g., stigma attached to suicide and survivor bias). Another issue is that these surveys, APS versus RHS, are administered by different organizations. Each one uses different sampling frames, questions, and sequencing and placement of questions, which could impact estimate comparability [42]. Divergence also occurs for data linkage potential. Statistics Canada (in-house) can combine APS and census information by way of personal identifiers (name, date of birth, residence, etc.) and can add information from other surveys or administrative data sources. As for the RHS, the collection of personal information for linkage purposes is not done.

Overall, this summary identified a number of potential data sources, including their strengths and weak- 
nesses for suicide reporting amongst Indigenous populations in Canada. The next two sections report on how we accessed multiple sources of administrative data and then survey data to improve suicide reporting for Canada's First Nations population in the Province of Manitoba.

\section{Manitoba case study - administrative data}

To estimate suicide patterns for the Province of Manitoba First Nations population, we accessed administrative data from the Population Health Research Data Repository at the Manitoba Centre for Health Policy (MCHP) for the period 1984 to 2008. To disaggregate the data for comparing First Nations and All Other Manitobans (AOM), we applied for and received the Indian Registry System file (IRS) from the federal Indigenous Affairs department, with permission from the regional First Nations organization. While this registry represents First Nations with government approved registration status in accordance with the Indian Act, it does not include First Nations not yet registered and excludes First Nations due to the legal criteria used to define a First Nations under the Indian Act. Reported in two separate papers $[31,44])$, we documented the history of this legal criteria, how it changed over time, and refined a previous linkage technique [45] to capture those not registered but eligible and include those not eligible due to a parent's type of legal registration status but who would still count as a First Nation because their parents were still registered First Nations. The process, in summary, involved linking at the individual level the IRS file to the Province of Manitoba Health Population Registry file and then linking the new linked key file to the MCHP registry file. In the MCHP registry file, there is a family number that is assigned to each individual of a family unit. This number is recorded on each individual's provincial health card and has been used to identify intergenerational linkages. By way of an intergenerational linkage, we were able to resolve some of the underreporting of First Nation children and adults (with Indian status but not registered and those with Indian status heritage but ineligible for status designated in law), with gains realized in the age groups 25 years and under, which improved the data for conditions prevalent in younger populations, such as suicide [31]. In addition to a First Nations identifier, the IRS file included on and off reserve residency status and the Manitoba population registry file included a postal code. Via these measures, we were able to geocode First Nations residency for sub-regional analyses.

This key file was then linked to the Manitoba vital statistics file (mortality) and to the physician and hospital databases. For our investigation of suicide behaviors, we used previously validated indicators for suicide attempt and suicide completion definitions from the Manitoba Centre for Health Policy concept dictionary [46]. These indicators reflect a suite of suicide behaviors identified within administrative databases. In this dictionary, a suicide attempt and self-inflicted injury that did not result in death was defined by ICD-9 and 10 codes from the hospital abstracts (ICD-9: E950E959, ICD-10-CA: X60-X84) and for a hospitalization with a diagnosis code for accidental poisoning (ICD9-CM: 965, 967, 969, 977.9, 986, E850-E854, E858, E862, E868; ICD-10-CA: T39, T40, T42.3, T42.4, T42.7, T43, T50.9, T58, X40-X42, X44, X46, X47, Y10-Y12, Y16, Y17) only if there was a physician visit with a diagnostic code for accidental poisoning and a psychiatric tariff code from the psychiatric schedule (8444, 8446, 8472, 8475-6, 8503-4, 8553-4, $8554,8581,8584,8588,8596)$ or the general schedule $(8580,8587$ and 8589) either during the hospital stay or within 30 days post-discharge. In the dictionary, a suicide completion was defined as the act of intentionally killing oneself by whatever means and was defined by ICD-9 or ICD-10 codes for self-inflicted injury or self-poisoning recorded as the primary cause of death in the Manitoba Vital Statistics data. While these codes are helpful in identifying suicide behavior, they can also be misleading which is discussed later in this section.

The population denominator was First Nations N $=787,363$ and AOM N =9,230,455 and was derived from the Manitoba population registry. Sex differences were investigated, including change over time with age-adjusted rates (per 10,000 residents) for ages 10 and older for the years 1984 to 2008. To aid interpretation, smoothing cubic splines provided curves that smoothed the discrete, non-linear data. 95 percent confidence intervals were then fitted to the smoothed curves. Smoothing splines was selected as a method for performing nonparametric regression. Over the same period, suicide methods were also reported as a percentage attributable to each method. For a ten-year period 1997 to 2006, age-specific rates per 10,000 residents aged 10 and older were then graphed. The tenyear period complied with provincial privacy legislation, which required sufficient counts for rate estimation. For geographic reporting, age-adjusted rates per 


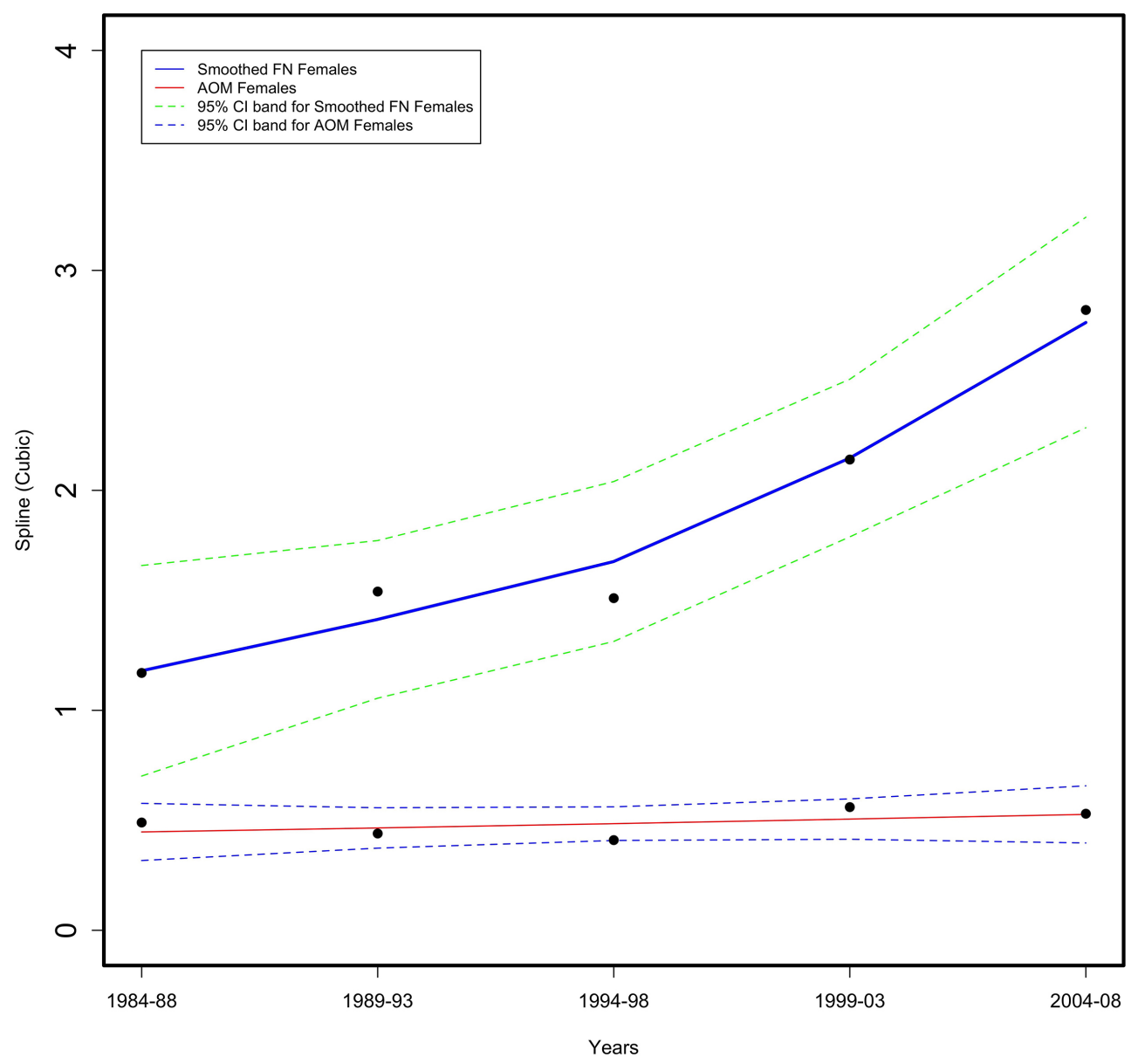

Fig. 1. Age adjusted First Nation (FN) versus All Other Manitoba (AOM) female provincial suicide rate per 10,000 for 5-year periods from 1984-2008 in the Province of Manitoba (vital statistics data).

10,000 residents were estimated for five regional health authorities, representing the east, west, north, south and the largest urban centre, Winnipeg. In these regions, rate comparisons were made for First Nations residing on-and-off reserve. These analyses included a comparison of the groups' rate to the provincial average. Statistical differences were tested at a probability of less than 0.01 due to multiple comparisons and to avoid an inflated type one error. SAS software was used to calculate rates and test group differences. The following is a summary of findings.

\subsection{Suicide rates overtime}

For the period 1984-2008, a spline analysis showed that First Nations female suicide completions were higher than All Other Manitoban (AOM) females with the rate steadily increased to a four-fold difference at 2004-08 (as shown in Fig. 1). For intentional suicide injuries, the First Nations female rate was 10 times greater than AOM females in the period 1984-1988 (as shown in Fig. 2). The First Nations female rate remained high until after 1994-1998, when the rate steadily declined but was still statistically greater, five times the AOM female rate.

For First Nation males, suicide completions were statistically two times greater than the AOM male rate in 1984 to 1988 (as shown in Fig. 3). By 1989-93, the First Nations male rate decreased but was not statistically different from the AOM male rate. In 199496, the First Nations male rate increased as the AOM male rate decreased, resulting in a statistical difference. First Nations male completions were at their highest in 1999-2003 while the AOM male rate remained steady. By 2004-2008, the First Nations male rate slightly declined but was still statistically greater, approximating the 1984-88 rate. For suicide attempts (as shown in Fig. 4), First Nations male rates were nine times 


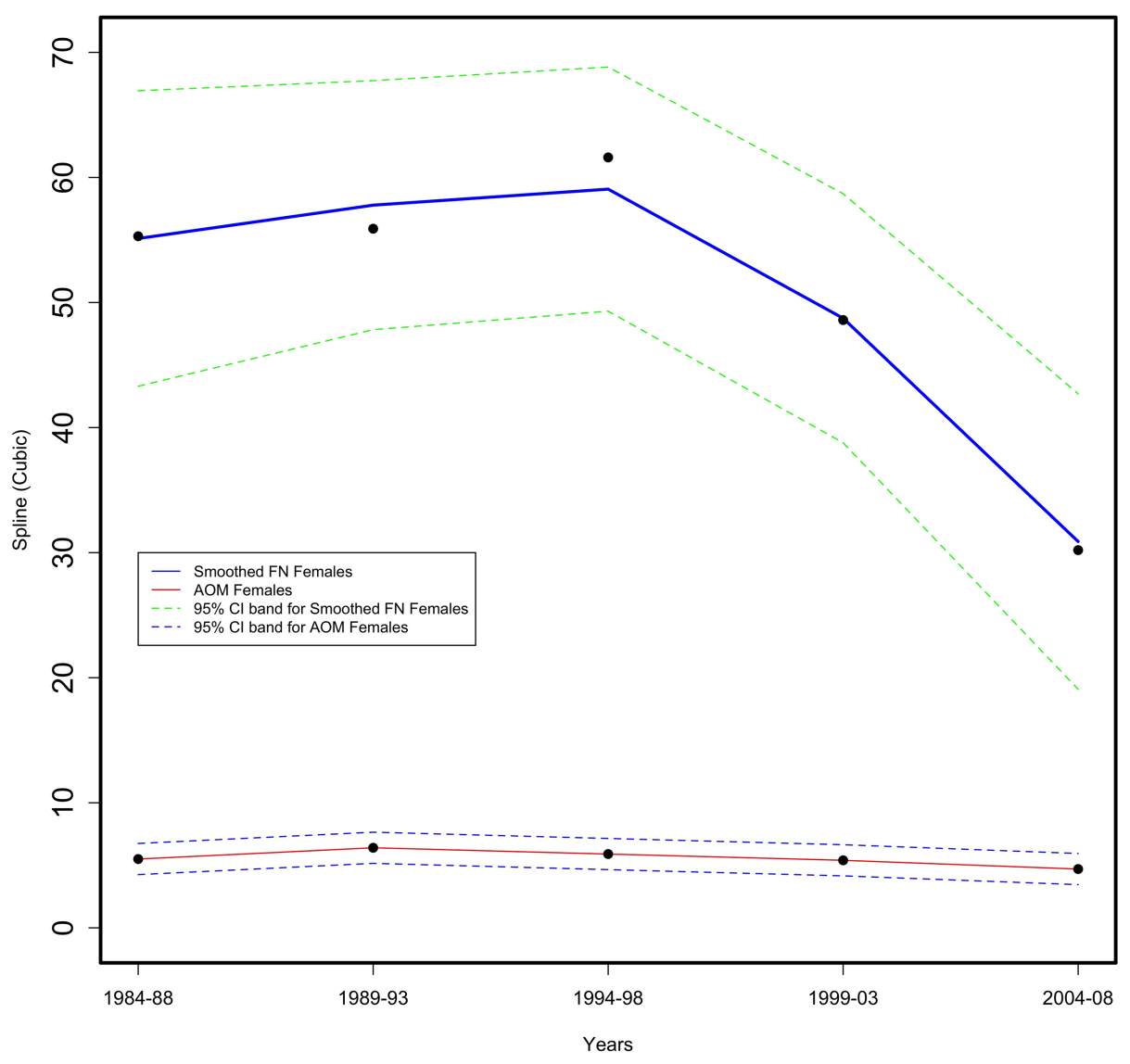

Fig. 2. Age adjusted First Nation (FN) versus All Other Manitoba (AOM) female provincial suicide attempt rate per 10,000 for 5-year periods from 1984-2008 in the Province of Manitoba (physician and hospital data).

greater than AOM males in the period 1984-1988. After 1994-1998, the First Nations male rate steadily declined while the AOM male rate changed little. By 2004-2008, although the First Nations male rate declined four points, it was still statistically five times greater than the $\mathrm{AOM}$ male rate.

\subsection{Period-specific suicide rates}

In the period 1997-2006, male suicide rates were higher than females regardless of group, whereas the opposite was true for attempts where there was a greater female risk (See supplemental Figs 1 and 2). First Nation rates, regardless of sex, were higher than the AOM rates, for either attempts or suicides. Agespecific rates for suicide attempts peaked for First Nation males at 20-24 years $(53 / 10,000)$ and for First Nation females at the ages of 15-19 (121/10,000). Agespecific suicide completion rates were highest for First Nation males at $15-19$ years $(10.5 / 10,000)$ and then declined after age 25 years. For First Nation females, the rates peaked at $15-19$ years $(5.0 / 10,000)$, declined, and then increased to $4.5 / 10,000$ by $35-39$ years. Rates for both sexes then dramatically declined. Rates in the AOM population, regardless for sex, had increased with age.

\subsection{Period specific sub-regional rate comparisons}

For the period 1997-2006, First Nation males on average were six times more likely to attempt suicide than AOM males, regardless of the regional health authority (RHA) in which they lived (as shown in Table 1). While sub-regional rates did not differ from the provincial average, the highest suicide attempt rates $(30.9 / 10,000)$ were found within the north. First Nation females were over seven times more likely than AOM females to attempt suicide. The attempt rate for northern First Nation females was significantly greater than the First Nation provincial average (First Nations 62.2 versus $44.7 / 10,000, p<0.01$ ). For AOM females, 


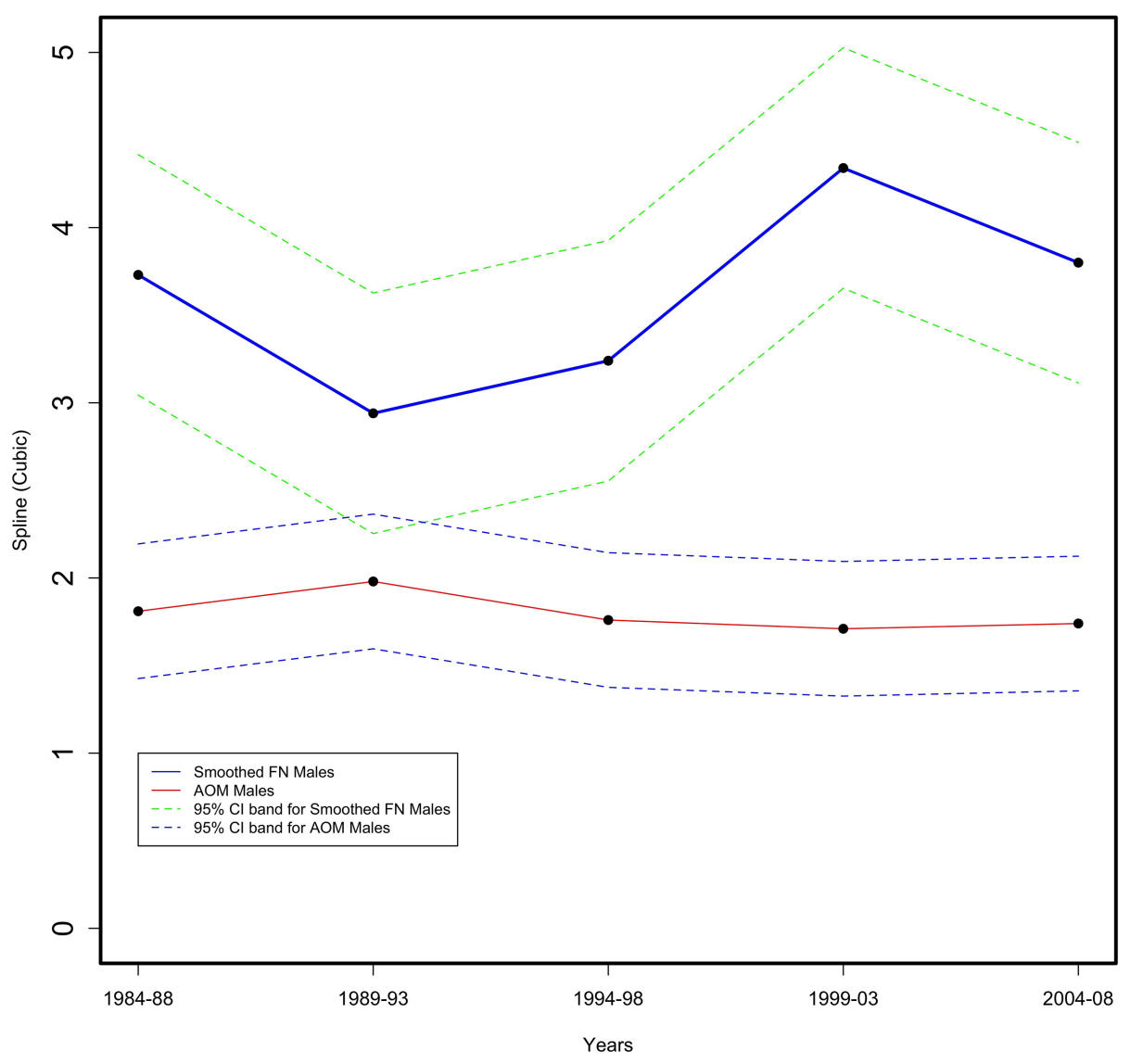

Fig. 3. Age adjusted First Nation (FN) versus All Other Manitoba (AOM) male provincial suicide rate per 10,000 for 5-year periods from 1984-2008 in the Province of Manitoba (vital statistics data).

northern attempt rates were also high, double the average (AOM 13.5 versus 6.1/10,000, $p<0.01$ ).

In the same period (as shown in Table 2), provincial suicide completion rates were three times higher for First Nation males, compared to AOM males (6.3 versus 2.0/10,000, $p<0.01)$. Completion patterns were similar among males, regardless of group or region. Also, First Nation females were five times more likely to complete suicide than AOM females. Northern First Nation females had higher counts of completing suicide than AOM northern females, whereas the reverse was true in the south where AOM female counts were greater. Counts lower than five, however, were found for northern AOM females and southern First Nation females, resulting in data suppression. Suicide completion rates, on average, were higher for First Nation on-reserve (on) males than those living off reserve (off) (on $=6.4$ versus off $=4.4 / 10,000 ; p<$ $0.0)$. For females, the provincial on-reserve rate was marginally but significantly lower than the off-reserve rate $(2.9$ versus $3.1 / 10,000, p<0.01)$. Sub-area dif- ferences were difficult to assess due to data suppression. Low counts occurred in the north, south and west for First Nation females living off reserve. Completion counts were suppressed for on-reserve First Nation females in the north and south. On average, First Nation on-reserve males $(32.9 / 10,000)$ had a significantly higher suicide attempt rate than First Nation males residing off reserve $(23.7 / 10,000)$. In the north, on-reserve First Nation males $(39.3 / 10,000)$ were significantly more likely $(p<0.01)$ to attempt suicide than off-reserve males $(27.3 / 10,000)$. Provincially, onreserve First Nation females were significantly more likely to attempt suicide than off-reserve First Nation females (on $=74.6$ versus off $=48.0 / 10,000, p<$ 0.01). For off-reserve females, the northern attempt rate was significantly greater than the provincial average (87.4 versus 48.0/10,000, $p<0.01)$.

\subsection{Suicide methods}

Over the 25-year period (1984-2008), out of all suicide methods, self-poisoning had, by far, the highest 


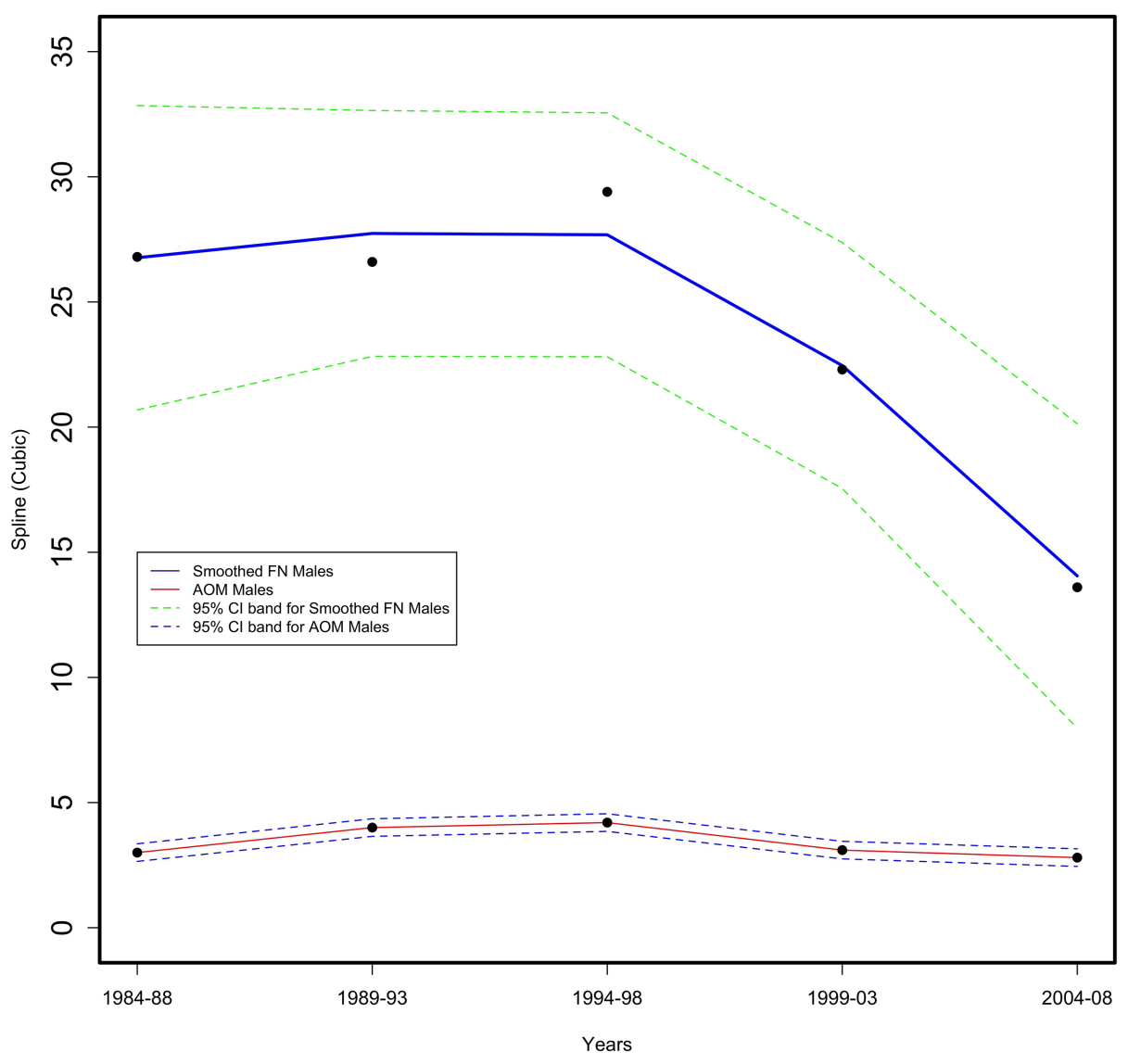

Fig. 4. Age adjusted First Nation (FN) versus All Other Manitoba (AOM) male provincial suicide attempt rate per 10,000 for 5-year periods from 1984-2008 in the Province of Manitoba (physician and hospital data).

prevalence regardless of group (as shown in Table 3). The percentage of self-poisoning was higher for females ( $\sim 87$ percent First Nations; 89 percent AOM) than males (First Nations $\sim 67$; $\sim 76$ AOM). However, this method increased over time for First Nation males (64.5 to 77.4 percent) while decreasing for First Nation females (91.7 to 86.1 percent). In this period, the proportion of attempts attributed to firearms greatly decreased for males (First Nation 9 to 2 percent; AOM 5.3 to 1.1 percent) and approximated the percentage for females (under two percent), regardless of group. For completed suicides, the use of firearms also declined for all groups and sexes (First Nation females 9.5 to 1.8 percent; First Nation males 40.0 to 9.9 percent; AOM females 13.2 to 1.4 percent plus; AOM males 50.2 to 20.6 percent). In its place, hanging increased for all groups and sexes (First Nation females 23.8 to 70.6 percent; First Nation males 44.3 to 71.4 percent; AOM females 15.8 to 30.5 percent plus; AOM males 18.6 to 35.3 percent). The percentage attributed to selfpoisoning also increased from 25.4 to 33.3 percent for
AOM males and from 11.4 to 14.4 percent for First Nation males. A decrease, however, was seen for First Nation females with percent attributed falling from 57.1 to 27.1 percent, while the percentage for AOM females oscillated from year to year within a range of 52.4 to 65.5 percent. The percentage attributed to other methods, while low, also declined for females regardless of group but increased for AOM and First Nation males.

\subsection{Summary}

These data confirmed for the 25-year period a higher male suicide risk and a significantly higher First Nations suicide risk when compared to the AOM population $[35,36]$. That being said, the First Nations and AOM male suicide rate for the period 2004-08 approximated the 1984-88 rate, while the First Nations female rate increased after 1994-98 resulting in a significant rate difference between First Nation females and AOM females. After 1998, the First Nation suicide attempt rates decreased but a significant gap between 
Table 1

Age adjusted rate per 10,000 residents age 10+ by sex for geographic health authority areas comparing First Nations and All Other Manitobans (AOM) for the period 1997-2006 in the Province of Manitoba (vital statistics data, physician data, hospital data)

\begin{tabular}{|c|c|c|c|c|c|c|c|c|}
\hline \multicolumn{2}{|c|}{ Suicide behavior } & $\begin{array}{l}\text { First } \\
\text { Nations } \\
\text { count }\end{array}$ & $\begin{array}{l}\text { First } \\
\text { Nations } \\
\text { pop. }\end{array}$ & $\begin{array}{l}\text { First Nations } \\
\text { adjusted rate } \\
\text { (Adj. CI) }\end{array}$ & $\begin{array}{l}\text { AOM } \\
\text { count }\end{array}$ & $\begin{array}{l}\text { AOM } \\
\text { pop. }\end{array}$ & $\begin{array}{l}\text { AOM } \\
\text { adjusted } \\
\text { rate } \\
\text { (Adj. CI) }\end{array}$ & $\begin{array}{l}\text { Relative disparity } \\
\text { rate ratio }\end{array}$ \\
\hline \multicolumn{9}{|c|}{ FIRST NATIONS/AOM } \\
\hline \multicolumn{9}{|c|}{ Sucide attempts } \\
\hline \multirow[t]{6}{*}{ Male } & Manitoba $^{\mathrm{d}}$ & 1069 & 385211 & 22.7 & 1681 & 4521024 & 3.7 & $6.11(4.80-7.77)$ \\
\hline & East $^{\text {aom, d }}$ & 127 & 64311 & $17.7(13.1-23.8)$ & 94 & 440731 & $2.2(1.6-3.0)$ & $7.94(5.55-11.35)$ \\
\hline & North ${ }^{\text {aom, }}$ d & 551 & 144496 & $30.9(24.0-39.7)$ & 94 & 137779 & $6.7(4.9-9.1)$ & $4.61(3.34-6.37)$ \\
\hline & South ${ }^{\mathrm{d}}$ & 48 & 25973 & $16.5(11.3-24.0)$ & 215 & 628865 & $3.4(2.6-4.5)$ & $4.82(3.25-7.15)$ \\
\hline & West $^{\mathrm{d}}$ & 130 & 47893 & $23.6(17.5-31.7)$ & 273 & 644907 & $4.4(3.4-5.7)$ & $5.33(3.89-7.30)$ \\
\hline & Winnipegd & 213 & 102538 & $17.7(13.4-23.4)$ & 1005 & 2668742 & $3.7(3.0-4.7)$ & $4.75(3.59-6.27)$ \\
\hline \multirow[t]{7}{*}{ Female } & Manitoba $^{\mathrm{d}}$ & 2427 & 402152 & 44.7 & 2894 & & 6.1 & $7.28(6.06-9.73)$ \\
\hline & & & & & & 4709431 & & \\
\hline & East $^{\mathrm{d}}$ & 274 & 62734 & $35.2(28.3-43.8)$ & 212 & 430217 & $4.9(3.9-6.2)$ & $7.14(5.53-9.22)$ \\
\hline & North $^{\text {d,First Nations,aom }}$ & 1243 & 144254 & $62.2(51.5-75.1)$ & 195 & 126809 & $\begin{array}{l}13.5 \\
(10.7-17.0)\end{array}$ & $4.61(3.64-5.83)$ \\
\hline & South $^{\mathrm{d}}$ & 120 & 25839 & $36.5(28.2-47.3)$ & 365 & 626427 & $5.3(4.3-6.5)$ & $6.86(5.20-9.05)$ \\
\hline & West ${ }^{\mathrm{d}}$,aom & 342 & 51248 & $53.0(42.9-65.6)$ & 565 & 670473 & $\begin{array}{l}8.9 \\
(7.3-10.8)\end{array}$ & $5.96(4.77-7.45)$ \\
\hline & Winnipeg $^{\mathrm{d}}$ & 448 & 118077 & $29.1(23.7-35.8)$ & 1005 & 2855505 & $5.6(4.6-6.7)$ & $5.23(4.25-6.44)$ \\
\hline \multicolumn{9}{|c|}{ Suicide completion } \\
\hline \multirow[t]{6}{*}{ Male } & Manitoba $^{\mathrm{d}}$ & 216 & 385211 & 6.3 & 894 & 4521024 & 2.0 & $3.22(2.36-4.40)$ \\
\hline & East $^{\mathrm{d}}$ & 44 & 64311 & $7.9(5.1-12.1)$ & 102 & 440731 & $2.5(1.8-3.5)$ & $3.16(2.00-4.99)$ \\
\hline & North & 81 & 144496 & $6.4(4.4-9.3)$ & 29 & 137779 & $2.3(1.5-3.7)$ & $2.76(1.65-4.62)$ \\
\hline & South ${ }^{\mathrm{d}}$ & 12 & 25973 & $5.5(2.9-10.5)$ & 95 & 628865 & $1.6(1.2-2.3)$ & $3.39(1.74-6.59)$ \\
\hline & West $^{\mathrm{d}}$ & 35 & 47893 & $8.5(5.4-13.4)$ & 143 & 644907 & $2.3(1.7-3.2)$ & $3.70(2.31-5.90)$ \\
\hline & Winnipeg $^{\mathrm{d}}$ & 44 & 102538 & $5.0(3.3-7.7)$ & 525 & 2668742 & $1.9(1.5-2.6)$ & $2.57(1.70-3.90)$ \\
\hline \multirow[t]{6}{*}{ Female } & Manitoba ${ }^{\mathrm{d}}$ & 122 & 402152 & 3.1 & 278 & 4709431 & 0.6 & $5.31(3.82-7.38)$ \\
\hline & East $^{\mathrm{d}}$ & 27 & 62734 & $4.6(2.8-7.4)$ & 15 & 430217 & $0.4(0.2-0.7)$ & $12.47(6.29-24.70)$ \\
\hline & North & 26 & 144254 & $1.9(1.2-3.2)$ & s & $\mathrm{s}$ & & \\
\hline & South & $\mathrm{s}$ & $\mathrm{s}$ & & 20 & 626427 & $0.3(0.2-0.6)$ & \\
\hline & West $^{\mathrm{d}}$ & 16 & 51248 & $3.3(1.8-5.8)$ & 26 & 670473 & $0.4(0.3-0.7)$ & $7.98(4.06-15.69)$ \\
\hline & Winnipegd & 48 & 118077 & $4.2(2.8-6.4)$ & 212 & 2855505 & $0.7(0.6-1.0)$ & $5.71(3.82-8.53)$ \\
\hline
\end{tabular}

$p<0.01$ denoted as 'd' indicates a statistical difference between the two groups' rates for this area. 'First Nation' rate statistically different from 'First Nation' average; 'AOM' rate statistically different from 'AOM' average. Data for 2007 and 2008 missed due to time lag in validating methods data.

First Nations and AOMs remained. These changes overtime for the completion rate are unlike suicide patterns in New Zealand (Maori, non-Maori) where rates for both groups decreased regardless of sex [10]. Our analysis therefore challenged the theory that minority suicide rates move with the rates of the economically dominant population [47].

For age-specific rates (1997-2006), while suicide rates typically increased with age for AOMs, regardless of sex, the opposite was true for First Nations. Adolescent First Nation males and females typically had a higher suicide rate. The First Nations male rate only approximated the AOM male rate after the age of 50, whereas the First Nations female rate approximated the AOM female rate at age 70. Unlike First Nation males, the First Nation female suicide rate increased at age 25 and peaked at 39 years at a level approximating the rate at 19 years of age. Only after age 39 did the rate dramatically decrease to approximate the AOM female rate after the age of 50. This younger age of risk was supported by research in Australia, New Zealand and the United States $[3,10,48]$. The female-age associated increase has been noted among US American Indian and Alaska Natives [49] and Australian Indigenous women $[11,12]$. The increase among Indigenous females suggests that there are unique drivers, such as a disproportionate history of abuse, trauma and mental health sequelae [50,51].

In addition, our findings confirmed that deviation and convergence in behavior is geographic [33]. While First Nations suicide behavior was significantly higher than AOMs regardless of geographic residence, there were significant geo-group variations. Attempted suicides were highest (regardless of sex) among First 
Table 2

Age adjusted rates per 10,000 residents age 10+ by sex for On-Reserve (ON) and Off-Reserve (OFF) First Nations population in geographic health authority areas for a ten-year snap-shot period 1997-2006 in the Province of Manitoba (vital statistics data, physician data, hospital data)

\begin{tabular}{|c|c|c|c|c|c|c|c|c|}
\hline \multicolumn{2}{|c|}{ Suicide behavior } & \multirow{3}{*}{$\begin{array}{l}\begin{array}{l}\text { OFF } \\
\text { count }\end{array} \\
383\end{array}$} & \multirow{4}{*}{$\begin{array}{l}\text { OFF } \\
\text { pop. } \\
\\
176545 \\
14598\end{array}$} & \multirow{4}{*}{$\begin{array}{l}\text { OFF adjusted } \\
\text { rate (Adj. CI) } \\
\\
23.7 \\
19.9(13.0-30.4)\end{array}$} & \multirow{4}{*}{$\begin{array}{r}\text { ON } \\
\text { count } \\
\\
686 \\
99\end{array}$} & \multirow{4}{*}{$\begin{array}{l}\text { ON } \\
\text { pop. } \\
\\
208666 \\
46713 \\
\end{array}$} & \multirow{4}{*}{$\begin{array}{l}\text { ON adjusted } \\
\text { rate (Adj. CI) } \\
\\
32.9 \\
21.9 \\
(16.6-23.7)\end{array}$} & \multirow{4}{*}{$\begin{array}{l}\begin{array}{l}\text { Relative disparity } \\
\text { rate ratio } \\
\text { (OFF/ON) }\end{array} \\
0.72(0.52-1.00) \\
0.91(0.58-1.44)\end{array}$} \\
\hline Suicide a & & & & & & & & \\
\hline Male & Manitoba $^{\mathrm{d}}$ & & & & & & & \\
\hline & East $^{\text {on }}$ & 28 & & & & & & \\
\hline & North $^{\mathrm{d}}$ & 74 & 28010 & $27.3(20.1-37.3)$ & 477 & 116486 & $\begin{array}{l}39.3 \\
(31.9-48.3)\end{array}$ & $0.70(0.51-0.95)$ \\
\hline & South $^{\mathrm{d}}$ & 11 & 9705 & $11.1(5.9-20.7)$ & 37 & 16268 & $\begin{array}{l}24.1 \\
(16.5-35.1)\end{array}$ & $0.46(0.23-0.93)$ \\
\hline & West & 57 & 21694 & $25.8(18.5-36.1)$ & 73 & 26199 & $\begin{array}{l}29.6 \\
(22.0-40.0)\end{array}$ & $0.870 .59-1.29)$ \\
\hline & Winnipeg & 213 & 102538 & $21.0(13.8-32.2)$ & - & - & - & - \\
\hline \multirow[t]{6}{*}{ Female } & Manitoba $^{\mathrm{d}}$ & 935 & 202129 & 48.0 & 1492 & 200023 & 74.6 & $0.64(0.51-0.82)$ \\
\hline & East $^{\text {on }}$ & 54 & 15772 & $37.6(27.6-51.2)$ & 220 & 46962 & $\begin{array}{l}49.6 \\
(40.6-60.5)\end{array}$ & $0.76(0.54-1.05)$ \\
\hline & North ${ }^{\text {off }}$ & 234 & 32165 & $71.2(58.2-87.2)$ & 1009 & 112089 & $\begin{array}{l}87.4 \\
(74.5-102.5)\end{array}$ & $0.81(0.67-1.00)$ \\
\hline & South ${ }^{\text {on }}$ & 50 & 11017 & $45.4(33.0-62.5)$ & 70 & 14822 & $\begin{array}{l}48.5 \\
(36.7-64.2)\end{array}$ & $0.94(0.63-1.39)$ \\
\hline & West & 149 & 25098 & $60.2(48.0-75.5)$ & 193 & 26150 & $\begin{array}{l}78.0 \\
(63.5-95.8)\end{array}$ & $0.77(0.60-1.00)$ \\
\hline & Winnipeg $^{\text {off }}$ & 448 & 118077 & $38.6(34.5-43.3)$ & - & - & - & - \\
\hline \multicolumn{9}{|c|}{ Suicide completion } \\
\hline \multirow[t]{6}{*}{ Male } & Manitoba $^{\mathrm{d}}$ & 82 & 176545 & 4.4 & 134 & 208666 & 6.4 & $0.69(0.52-0.91)$ \\
\hline & East & 8 & 14598 & $5.3(2.6-11.0)$ & 36 & 449713 & $\begin{array}{l}7.5 \\
(5.2-10.8)\end{array}$ & $0.71(0.33-1.54)$ \\
\hline & North & 16 & 28010 & $5.4(3.2-9.3)$ & 65 & 116486 & $5.5(4.1-7.4)$ & $0.99(0.57-1.70)$ \\
\hline & South & - & - & - & 8 & 16268 & $4.8(2.4-9.9)$ & - \\
\hline & West $^{\mathrm{d}}$ & 10 & 21694 & $4.3(2.8-5.8)$ & 25 & 26199 & $\begin{array}{l}9.6 \\
(6.3-14.7)\end{array}$ & $0.45(0.21-0.93)$ \\
\hline & Winnipeg & 44 & 102538 & $4.1(2.8-5.8)$ & - & - & - & - \\
\hline \multirow[t]{6}{*}{ Female } & Manitoba $^{\mathrm{d}}$ & 64 & 202129 & 3.1 & 58 & 200023 & 2.9 & $1.06(0.74-1.51)$ \\
\hline & East & 6 & 15772 & $3.9(1.7-9.1)$ & 21 & 46962 & $4.6(2.8-7.5)$ & $0.86(0.35-2.14)$ \\
\hline & North & - & - & - & 22 & 112089 & $1.9(1.2-3.2)$ & - \\
\hline & South & - & - & - & - & - & - & - \\
\hline & West & - & - & - & 13 & 26150 & $5.0(2.7-9.1)$ & - \\
\hline & Winnipeg & 48 & 118077 & $5.7(3.9-8.2)$ & - & - & - & - \\
\hline
\end{tabular}

"ON" rate statistically different from ON average; "OFF" rate statistically different from OFF average; "d" group area rate statistically different. Statistical significance is $p<0.01$ There is no "ON" reserve population in Winnipeg. "-" data suppressed for counts under five.

Nations living on reserve as opposed to those living off-reserve. While the off-reserve analyses showed a high First Nations urban female suicide attempt burden, the highest rates were found among northern offreserve First Nation females (including among AOM females in that region). This research confirmed gendered geographic behavior variability, which has been found among particular United States Indian Health Service regions for the American Indian and Alaska Native and white populations [6]. These findings suggest that sub-regional analyses are critical to understand gendered suicide behavior between and among groups. For methods of suicide, our results suggest that lethal means restriction may have had an im- pact in this period [52,53], particularly for First Nation males. While males tended to opt for more lethal means, a gender-role convergence in selecting alternative methods less amenable to restrictions seems to have occurred (hanging), which may explain the increased First Nation completion rates [54,55]. In countries where there are no means restrictions, such as the United States, the predominate method is still firearms across groups [48].

Like all studies, there were limitations and historical data challenges. Suicide completions may have been recorded as accidental in the vital statistics system. This is a problem which has been shown in studies linking examiner data with vital statistics data to 
Table 3

Percent attributed to method for suicide attempts and completions by sex comparing the First Nations and All Other Manitoban (AOM) population for five periods from 1984-2008 (highlighted areas show highest percent; - represents data suppressed under five) in the Province of Manitoba (vital statistics event data, physician data, hospital data)

\begin{tabular}{|c|c|c|c|c|c|c|c|c|c|c|}
\hline \multirow[t]{2}{*}{ Suicide behaviour } & \multicolumn{2}{|c|}{ Hanging } & \multicolumn{2}{|c|}{ Firearms } & \multicolumn{2}{|c|}{ Poison } & \multicolumn{2}{|c|}{ Cutting } & \multicolumn{2}{|l|}{ Other } \\
\hline & First Nations & $\mathrm{AOM}$ & First Nations & $\mathrm{AOM}$ & First Nations & $\mathrm{AOM}$ & First Nations & $\mathrm{AOM}$ & First Nations & AOM \\
\hline \multicolumn{11}{|l|}{ Suicide attempt } \\
\hline \multicolumn{11}{|l|}{ Female } \\
\hline $1984-88$ & 0.8 & 0.2 & 1.1 & 0.1 & 91.7 & 92.9 & 5.4 & 4.9 & 1.1 & 1.9 \\
\hline 1989-93 & 1.6 & 0.7 & 1.6 & 0.3 & 88.3 & 89.4 & 7.6 & 7.4 & 1.3 & 2.2 \\
\hline 1994-98 & 3.2 & 1.0 & 0.1 & 0.1 & 87.6 & 88.4 & 6.6 & 7.2 & 2.5 & 3.4 \\
\hline 1999-03 & 5.3 & 1.0 & 0.1 & 0.2 & 87.2 & 88.8 & 5.7 & 7.5 & 1.6 & 2.6 \\
\hline 2004-08 & 3.0 & 0.6 & - & 0.1 & 86.1 & 92.1 & 9.3 & 5.5 & 1.7 & 1.7 \\
\hline \multicolumn{11}{|l|}{ Male } \\
\hline $1984-88$ & 4.7 & 3.4 & 19.3 & 5.3 & 64.5 & 78.8 & 8.4 & 11.3 & 3.1 & 1.3 \\
\hline 1989-93 & 5.0 & 2.1 & 14.4 & 2.5 & 62.6 & 75.6 & 12.5 & 14.1 & 5.5 & 5.7 \\
\hline 1994-98 & 7.4 & 1.8 & 8.1 & 1.9 & 67.0 & 74.6 & 12.7 & 15.5 & 4.9 & 6.3 \\
\hline 1999-03 & 10.9 & 2.8 & 2.1 & 0.7 & 69.4 & 78.7 & 11.9 & 12.5 & 5.7 & 5.3 \\
\hline 2004-08 & 7.8 & 2.4 & 2 & 1.1 & 77.4 & 79.9 & 10.1 & 13.1 & 2.8 & 3.5 \\
\hline \multicolumn{11}{|l|}{ Suicide completion } \\
\hline \multicolumn{11}{|l|}{ Female } \\
\hline 1984-88 & 23.8 & 15.8 & 9.5 & 13.2 & 57.1 & 52.6 & - & 3.9 & 9.5 & 14.5 \\
\hline 1989-93 & 45.5 & 17.7 & 9.1 & 8 & 42.4 & 62.8 & - & 0.9 & 3.0 & 10.6 \\
\hline 1994-98 & 52.9 & 30.5 & - & 1.9 & 41.2 & 52.4 & 5.9 & 2.9 & - & 12.4 \\
\hline 1999-03 & 62.5 & 29.3 & 1.8 & 1.4 & 33.9 & 59.9 & - & 2 & 1.8 & 7.5 \\
\hline 2004-08 & 70.6 & 26.8 & - & 1.4 & 27.1 & 65.5 & - & - & 2.4 & 6.3 \\
\hline \multicolumn{11}{|l|}{ Male } \\
\hline $1984-88$ & 44.3 & 18.6 & 40.0 & 50.2 & 11.4 & 25.4 & 1.4 & 1 & 2.9 & 4.7 \\
\hline 1989-93 & 46 & 26.7 & 36.5 & 37.9 & 6.3 & 27.7 & 4.8 & 1.7 & 6.3 & 6.0 \\
\hline 1994-98 & 69.3 & 31.9 & 18.1 & 31.2 & 8.3 & 28.7 & 1.4 & 0.9 & 2.8 & 7.3 \\
\hline 1999-03 & 71.4 & 30.8 & 10.7 & 25.7 & 11.6 & 33.3 & 2.7 & 2.3 & 3.6 & 7.9 \\
\hline 2004-08 & 71.2 & 35.3 & 9.9 & 20.6 & 14.4 & 34.0 & 0.9 & 2.6 & 3.6 & 7.5 \\
\hline
\end{tabular}

verify suicide deaths and to resolve potential death misclassification [30]. In addition, the Manitoba Centre for Health Policy definition for suicide attempt did not include ICD-9-CM V62.84 supplemental code for suicide ideation or ICD-10 T14.91 for unspecified injury suicide attempt. With the rise of non-suicidal self-mutilation (impulse control disorder), the clinical coding of self-mutilation only (ICD-9-CM 300.9) versus suicide intended cutting injuries (E956) needs more research, including the way impulsive suicides are coded. Furthermore, we did not distinguish suicide attempts by number of attempts. In the Manitoba population, for the period 1997-2007, we did note that 74 percent had attempted suicide only once, while 26 percent had attempted suicide two or more times. Future research should investigate how these groups differ using person-centered statistics. There were also potential misclassification issues, particularly when classifying suicide self-harm due to non-violent means like poisoning [56]. A recent study of suicide underreporting using external cause of injury codes from Statistics Canada mortality data from 2000 to 2011 supports this concern [57]. In that study, suicide by poisoning rates declined, while unintentional and un- determined poisoning mortality rates increased, thus showing that Canada may have a misclassification issue pertaining to poisoning deaths. Death by poisoning or drug overdose, for instance, is difficult to classify as suicide when intent is not evident (e.g., a suicide note). To improve reporting, Donaldson et al. [58] created a decision algorithm by using past behavior and health conditions (suicide attempt, drug abuse, physical health problems, depressed mood) to distinguish unintentional and suicide poisoning deaths. Using this approach, they determined that suicide by poisoning rates were under-reported 30 percent of the time and 10 percent of the time for overall suicide rates. They also found that unintentional poisoning deaths were underreported by 61 percent. These misclassification aspects may explain some of the changes in suicide by poisoning in our analyses.

\section{Manitoba case study: Survey data}

While the administrative data told a compelling suicide behavior story, these data lacked measures to fully describe factors associated with that behavior. Popula- 
tion surveys, as noted, can address this gap by revealing what is driving rates across populations [59-62]. To identify social determinants of suicide behavior, we used Manitoba regional data from the First Nations Regional Health Survey of adults and youth [51,63]. The 2002-2003 dataset for Manitoba First Nation living on reserve included national questions and a subset of regionally developed social determinant questions on suicide behavior and protective factors. From the 2002-2003 adult data, we investigated First Nation adult suicide behaviors in relation to historical and contemporary trauma and the residential school system [51]). We conducted a logistic regression analysis of a history of suicide thoughts $(n=2688)$, suicide attempts $(n=2728)$ and abuse experience $(n=2652)$, with the later being a predictor of suicide. The analyses showed, overall, that being female (log odds $2.50, \mathrm{CI}$ 2.00-3.13), having no partner (log odds 1.37, CI 1.031.81), having attended a residential school (log odds 2.00, CI 1.36-2.93), and having a parent/grandparent who attended a residential school (log odds $1.88, \mathrm{CI}$ 1.47-2.41) were associated with an abuse history. Age groups 18-27 years ( $\log$ odds 1.58, CI 1.06-2.35) and 28-44 years ( $\log$ odds 1.75 , CI 1.19-2.59), being female (log odds 1.46 , CI 1.14-1.87), having no partner (log odds 1.30, CI 1.03-1.65) and having a parent/grandparent who attended a residential school (2.02, CI 1.51-2.70) were associated with a history of suicide thoughts. Being female (log odds 1.94, CI 1.49-2.54), having no partner (log odds 1.40 , CI 1.03 1.92) and having a parent/grandparent who attended a residential school was associated with a suicide attempt history. Within the First Nations cohort who attended a residential school, logistic regression analyses were run for a history of abuse $(n=507)$, suicide thoughts $(n=494)$ and suicide attempts $(n=487)$. First Nation residential school attendees who disclosed that they were negatively affected while in a residential school (log odds 3.83, CI 2.09-7.02) were more likely to have a lifetime history of abuse. This abuse history (log odds 5.89, CI 2.61-13.27) and being 28-44 years of age (log odds 2.16, CI 1.17-4.00) was associated with a history of suicide thoughts, while a suicide attempt history was solely associated with an abuse history (log odds 2.67, CI 1.21-5.89). In the cohort that did not attend a residential school, a logistic regression analysis characterized those who had a history of abuse ( $n=2010)$, suicide thoughts $(n=1877)$ and suicide attempts $(n=1911)$. Being $28-44$ years of age (log odds 1.58, CI 1.09-2.30), being female (log odds 2.95, CI 2.18-3.99), having no partner (log odds
1.43, CI 1.03-1.98), and having a parent/grandparent who attended a residential school (log odds 2.05 , CI 1.58-2.63) was associated with an abuse history. This trauma history was strongly associated with a history of suicide thoughts ( $\log$ odds 6.24, CI 4.24-9.17) and suicide attempts ( $\log$ odds 5.86, CI 3.53-9.73). After adjusting for an age $\mathrm{X}$ parent/grandparent residential school exposure interaction, the odds of having a history of suicide thoughts were increased for those 18-27 years, 28-44 years, and more so for those 45 years and older who had a parent/grandparent who attended a residential school. For a suicide attempt history, the age groups 18-27 years and 28-44 years who had a parent/grandparent who attended did not significantly differ from their counterparts. However, First Nation adults 45 years and older who had a parent/grandparent who attended a residential school were nearly three times more likely to have attempted suicide than those in the same age group that did not have a parent/grandparent that attended a residential school. These findings thus showed that the legacy of the residential school system was an intergenerational colonial correlate of adult First Nation suicide behaviors. This finding was supported by a review conducted by Bombay et al. [64], which summarized a small, but growing literature that confirms the link between familial intergenerational residential school attendance and suicide. A more recent study using 2008-2010 national First Nations Regional Health Survey adult data also verified the link between intergenerational residential school exposure and suicide [65]. These intergenerational colonial impacts have been noted elsewhere. A United States study of Indian Boarding School experience among urban two-spirited American Indians and Alaska Natives found that former boarding school attendees were significantly more likely to have attempted suicide or had experienced suicide thoughts, when compared to those with no boarding school history. Also, those who were raised by a boarding school attendee were significantly more likely to have a lifetime of suicidal thoughts, when compared to others [66]. More research, however, is required to assess this pattern beyond the two-spirited population. In Australia, literature also supports that Indigenous suicide is a product of a colonial society, intergenerationally rooted to the stolen generation period (19051967), which is when mixed race Indigenous children were taken from their families and forced to live in religious missions, government institutions, or children homes [67]. Overall, more research is required to assess these patterns across countries. 
To understand patterns among youth, we analyzed data for on-reserve First Nations youth aged 12 to 18 years $(n=1125)$ from the Manitoba First Nations Regional Health Survey [63]. Our analyses showed an increased likelihood for suicide ideation and suicide attempts among those who were female (Log Odds 2.51, 1.03-6.1), binge drank in the past year (3.65, CI 1.0013.25), with a lifetime of drug use (Log Odds 6.82, CI 1.44-32.24), a depressed mood in the past year ( $\mathrm{Log}$ Odds 4.72, CI 1.32-16.9), a history of abuse or fear of abuse (Log Odds 2.43, CI 1.14-5.19), and a hospital stay (11.73, CI 2.13-64.75). Overall, these risk correlates were similar to those found in other populations [68-71]. What was not associated with suicide behavior was an exposure to a parent who attended a residential school. This lack of an association was contrary to national findings of the youth component of the national First Nations Regional Health Survey database (2002-2003). In that study, 26.3 percent of First Nations youth with a residential school parent had a history of suicide thoughts, as opposed to 18 percent of non-residential school parent youth [72]. In our study, what was associated with no suicide ideation or attempts was perceived community caring (Odds Ratio 0.93, CI 0.88-0.97). This finding, which was not investigated nationally, reflected a form of cultural continuity as a hedge against suicide [73]. This construct appears to represent a collective form of cultural and intergenerational connectedness shared by Indigenous peoples. This connectedness could represent other traditional-cultural aspects such as Indigenous language and self-government, or more recently as a form of engagement in contemporary institutions (schools or municipal governments) [74].

In summary, we were able to show the legacy of the residential school system in relation to adult First Nations suicide behaviors, particularly First Nations women. For First Nations youth, while the correlates of suicide were similar to other populations, community caring emerged as a protective factor unique to First Nations. Like other surveys, our data was not free of limitations. First, the survey was cross-sectional, which only permitted an examination of associations as opposed to causal pathways. Recall and selection bias in responses may have also affected the findings (e.g., underestimation of a history of abuse and suicide reporting). Another limitation is that the social, historical and cultural measures were not previously validated. The survey did not include questions on a range of mental health conditions (beyond depression), which are known correlates of suicide. Equally as important and noted earlier, the study was limited to the on-reserve population.

\section{Conclusion}

This paper provided an overview of the strong social-political drivers that can improve Indigenous statistics, particularly for suicide. In Canada, opportunities to report Indigenous suicide via administrative and survey data sources are many, and the use of multiple data sources seems to improve reporting. The potential of using linked administrative data to understand suicide rates between and among groups overtime and geographically was demonstrated. Harnessing survey data provided insight into factors associated with suicide risk. We confirmed the role of the residential school system in suicide behavior, and found attributes of reconciliation (community caring) that can be protective. All told, access to administrative data, the ability to link and disaggregate data ethnoculturally, the merit of taking different approaches to estimate a story, and the increased value obtained from explaining rate patterns with population survey data is just one way that we can advance the use of statistics from an Indigenous and human rights perspective.

As this paper illustrated, disaggregating suicide indicators in Canada is more than a matter of will. Canada is obligated to report on the United Nations (UN) Sustainable Development Goals, to follow guidance provided by the UN High Commissionaire of Human Rights and the UN Statistical Commission, and to act constitutionally for and with Indigenous peoples by way of truth and reconciliation and in accordance with the UN Declaration of Indigenous peoples. These obligations include reporting suicide estimates disaggregated by Indigenous and non-Indigenous groups, sex, age, and geographic areas and by additional factors, including those unique to Indigenous populations. Our analyses demonstrated a need to strengthen capacity for monitoring the reduction of suicides among First Nations, with attention given to contemporary, colonial and cultural drivers of behavior. This capacity should also include monitoring suicide intervention programs, which is lacking. The main interventions that are not typically evaluated include community prevention, gatekeeper training and education. A review conducted of programs across Canada, the United States, Australia and New Zealand revealed that few programs report evidence of effective interventions [75]. One review called for increased evaluations using methodologically rigorous study designs across geographically and culturally diverse populations [76]. For example, a randomized trial of a Maori cultural identity intervention for those who recently self-harmed (ver- 
sus usual care) found little effect on suicide behavior but was protective for other conditions [77]. In a Manitoba tribal region, we evaluated a suicide intervention program (gatekeeper training) adopted by First Nations and Inuit communities across Canada using a randomized control trial design [78]. The study showed that the gatekeeper program, when compared to a traditional Indigenous wellness approach, had triggered thoughts of suicide among tribal community members. The findings of these two rigorous studies suggest that more research is needed to investigate, upstream and downstream, the complex drivers of suicide and its protective factors. Indeed, we recently published a data linkage study that showed that First Nation children diagnosed with fetal alcohol spectrum disorder (FASD) had significantly higher suicide behaviors than other First Nation children in Manitoba [79]. While impulse behavior is a co-occurring behavior of the FASD diagnosed, FASD and impulsivity is not fully understood in relation to suicide. Indeed, studies on attempt impulsivity have produced widely divergent results, thus showing a need for prospective studies linking behavioral impulsivity (and co-occurring conditions) with non-suicidal and suicidal injury or means [80].

In conclusion, this study has shown the value of data and its essential role in promoting Indigenous health and equity pertaining to suicide. To make progress, the following are a number of recommendations. New or renewed partnerships between governments and Indigenous authorities, are urgently required to ensure comparative data that is achievable, accountable, accessible, transparent and consistent with Indigenous principles of official statistics. Indigenous communities should be engaged, consistent with principles of Indigenous ownership and reporting. These partnerships should link internationally to collectively learn from each other. While review studies have played a critical role in advancing national suicide prevention policies, strategies and interventions, standardized period reporting is recommended to monitor suicide via a best practice lens. Beyond the reporting of rates, it is critical to monitor period-cohort effects due to policies, health and supportive services, social-economic crises, and the increase, decrease or shift in type of addictive drug use, which may impact one or more groups within a population [12]. Such surveillance should fall under Indigenous statistics with, for and by Indigenous peoples. Guidance on how best to select a standard population for rate calculation is also needed given that the Indigenous population is demographically younger than non-Indigenous popula- tions, particularly in regions colonized by western societies. Best practice linkage studies should be undertaken to enhance regional and national data collections and adjust for under identification of Indigenous peoples. Where records have incomplete identification or registration, multiple data sources should be considered [15]. Linking past behavior should be examined to address misclassification issues pertaining to, for example, unintentional, undetermined and intentional self-poisoning. These validation analyses are feasible if there is linkable physician and hospital stay data (morbidity), coroner data and vital statistics death data. Monitoring should also include data sources that permit an investigation into the historical, developmental and social factors of risk, including factors associated with prevention. To guide this work, an Indigenous evidence-based framework is recommended. We should also heed the words of Antonette White, who recalled a suicide event when the staff of an Indian residential school in British Columbia (Canada) forced students to look at a suicide victim: "I remember the young fellow that hung himself in the gym, and they brought us in there, and showed us, as kids, and they just left him hanging there, and like, what was that supposed to teach us?" [81]. This story, told with great courage, is a reminder that we have a moral responsibility in reporting. First, we must report suicides with compassion and understanding. Second, we do not report and do nothing. Third, we report to make transparent the societal harms that lead to such events, and fourth, we report evidence on how such events can be prevented using an Indigenous evidence-based framework.

\section{Acknowledgments}

The author acknowledges the Canadian Institutes of Health Research (HOA 80062) for funding this analysis. I further acknowledge the Assembly of Manitoba Chiefs and the Manitoba Centre for Health Policy for use of the data contained in the Population Health Research Data Repository under HIPC \# 2008/200940. Data used are from the Population Health Research Data Repository housed at the Manitoba Centre for Health Policy, University of Manitoba, and were derived from data provided by Manitoba Health and the Indigenous and Northern Affairs Canada. The results and conclusions presented are those of the author and no official endorsement by the Canadian Institutes of Health Research, Manitoba Health, the Assembly 
of Manitoba Chiefs, Indigenous and Northern Affairs Canada or other data providers is intended or should be inferred. These analyses support the efforts of the International Group of Indigenous Health Measurement to make a positive difference in liberating data for Indigenous peoples throughout the world.

\section{References}

[1] International Group for Indigenous Health Measurement. [Homepage on the Internet] Cited on 2018 August 25. Available from https://www.cdc.gov/nchs/isp/isp_multilateral_coll aborations.htm

[2] Pollock NJ, Naicker K, Loro A, Mulay S, Colman I. Global incidence of suicide among Indigenous peoples: A systematic review. BMC Medicine. 2018; 16: 145. doi: 10.1186/s12916018-1115-6.

[3] Hunter E, Harvey D. Indigenous suicide in Australia, New Zealand, Canada and the United States, Emergency Medicine Australasia 2002; 14(1): 14-24.

[4] Kirmayer LJ, Brass GM, Holton T, Paul K, Simpson C, Tait C. Suicide Among Aboriginal People in Canada. Ottawa, Canada: The Aboriginal Healing Foundation, 2007.

[5] Health Canada. A Statistical Profile of the Health of First Nations in Canada: Vital Statistics for Atlantic and Western Canada, 2003-2007, Ottawa: Health Canada; 2014; Cited on 2018 May 7. Available from http//publications.gc.ca/collec tions/collection_2014/sc-hc/H34-193-3-2014-eng.pdf.

[6] Herme MA, Bartholomew ML, Weahkee RL. Suicide mortality among American Indians and Alaska Natives, 19992009. American Journal of Public Health. 2014; 104(Suppl 3): S336-S342.

[7] De Leo D, Sveticic J, Milner A. Suicide in Indigenous people in Queensland, Australia: trends and methods, 1994-2007. Aust N Z J Psychiatry. 2011; 45(7): 532-8.

[8] Campbell A, Chapman M, McHugh C, Sng A, Balaratnasingam S. Rising Indigenous suicide rates in Kimberley and implications for suicide prevention. Australas Psychiatry. 2016; 24(6): 561-564

[9] McHugh C, Campbell A, Chapman M, Balaratnasingam S. Increasing Indigenous self-harm and suicide in the Kimberley: An audit of the 2005-2014 data. Med J Aust. 2016; 205(1): 33. doi: $10.5694 / \mathrm{mja} 15.01368$.

[10] Beautrais AL, Fergusson DM. Indigenous suicide in New Zealand. Archives of Suicide Research. 2006; 10(2): 159-168.

[11] Snowdon J. Changes in the age pattern of New Zealand suicide rates. New Zealand Medical Journal. 2006; 130(1448): 18-26.

[12] Snowdon J. Should the recently reported increase in Australian suicide rates alarm us? Australian \& New Zealand Journal of Psychiatry. 2017; 51(8): 766-769.

[13] Elias B, Busby K, Martens P. One little, too little: Counting Canada's Indigenous people for improved health reporting. Social Science \& Medicine. 2015; 138: 179-86.

[14] Smylie J, Firestone M. Back to the basics: identifying and addressing underlying challenges in achieving high quality and relevant health statistics for Indigenous populations in Canada, Statistical Journal of the IAOS. 2015; 31: 67-87.

[15] Coleman C, Elias B, Lee V, Smylie J, Waldon J, Hodge FS, Ring I. International Group for Indigenous Health Measurement: Recommendations for best practices for estimation for
Indigenous mortality. Statistical Journal of the IAOS. 2016; 32: 729-38.

[16] Anderson I et al. Indigenous and Tribal Peoples' Health (The Lancet-Lowitja Institute Global Collaboration): A population study. The Lancet. 2016; 388(10040): 131-157.

[17] Truth and Reconciliation Commission of Canada. Calls to Action. Winnipeg, Manitoba, Canada; 2015; Cited on 2018 May 9. Accessed from http//www.trc.ca/websites/trcinstitution/ File/2015/Findings/Calls_to_Action_English2.pdf.

[18] United Nations General Assembly, Transforming our world: the 2030 Agenda for Sustainable Development, A/RES/70/1, October 21, 2015. Cited on 2018 May 5. Accessed from http//www.un.org/ga/search/view_doc.asp?symbol=A/RES/ $70 / 1 \&$ Lang=E.

[19] United Nations. Everyone counts: Ensuring a response of official statistics to Sustainable Development Goals consistent with Human Rights, ECE/CES/2015/35, May 8, 2015. Cited on 2018 May 14. Access from http//www.ohchr.org/Documen ts/Issues/HRIndicators/35-OHCHR_seminar_SDG.pdf.

[20] Madden R, Axelsson P, Kukutai T, Griffiths K, Mienna S, Christina-Brown N, Coleman C, Ring I. Statistics on Indigenous peoples: An international effort needed. Statistical Journal of the IAOS. 2016; 32(1): 37-41.

[21] United Nations. Indigenous peoples and the 2030 agenda. Cited on 2018 October 12. Accessed from https//www.un.org/ development/desa/indigenouspeoples/focus-areas/post2015-agenda/the-sustainable-development-goals-sdgs-andindigenous/recommendations.html.

[22] Assembly of First Nations. The First Nations Health Transformation Agenda. 2017. Ottawa (Canada): Assembly of First Nations. Cited on 2018 October 12. Accessed from https//www.aFirstNations.ca/uploads/files/First Nation shta_final.pdf.

[23] Statistics Canada. Deaths and mortality rate, by selected grouped causes, sex and geography - Canada. Statistics Canada, 2012; Cited on 2018 May 5. Accessed from http// www.statcan.gc.ca/pub/84f0209x/2009000/t001-eng.htm.

[24] Statistics Canada. Suicides and suicide rate, by sex and by age group. Statistics Canada; 2012; Available from: URL: http//www.statcan.gc.ca/tables-tableaux/sum-som/101/cst01/ hlth66a-eng.htm.

[25] Statistics Canada. CANSIM, Table 102-0551; 2018; Cited on 2018 May 9. Accessed from https//www.statcan.gc.ca/tablestableaux/sum-som/101/cst01/hlth66d-eng.htm.

[26] World Health Organization. Classifications; 2009; Cited on 2018 May 9. Accessed from http://www.who.int/classificati ons/icd/en/.

[27] Navaneelan T. Suicide rates: An overview, Statistics Canada Catalogue no. 82-624-X, 2017. Cited on 2018 September 12. Accessed from https//www.150.statcan.gc.ca/n1/pub/82-624x/2012001/article/11696-eng.htm.

[28] Malla A, Hoenig J. Differences in suicide rates: an examination of under-reporting. Canadian Journal of Psychiatry. 1983; 28(4): 291-293.

[29] Speechley M, Stavraky KM. The adequacy of suicide statistics for use in epidemiology and public health. Canadian Journal of Public Health. 1991; 82(1): 38-42.

[30] Edwards N, Reza A, MacDonald D, Sikdar K, Collins K, Avis S. Suicide in Newfoundland and Labrador: a linkage study using medical examiner and vital statistics data. Canadian Journal of Psychiatry. 2008; 53(4): 252-259.

[31] Elias B. Moving beyond the historical quagmire of measuring infant mortality for the First Nations population in Canada. Social Science and Medicine. 2014; 123: 125-132. 
[32] Oliver LN, Finès P, Bougie E, Kohen D. Intentional injury hospitalizations in geographical aeas with a high percentage of Aboriginal-identity residents, 2004/2005 to 2009/2010. Chronic Diseases and Injuries in Canada. 2014; 34(2-3): 8293.

[33] Pollock NJ, Mulay S, Valcour J, Jong M. Suicide Rates in Aboriginal Communities in Labrador, Canada. American Journal of Public Health. 2016; 106(7): 1309-1315.

[34] Carrière G, Bougie E, Kohen D, Rotermann M, Sanmartin C. Acute care hospitalization by Aboriginal identity, Canada, 2006 through 2008. Health Reports 2016; Ottawa: Statistics Canada. Cited 2018 September 10. Accessed from https//www.150.statcan.gc.ca/n1/en/pub/82-003x/2016008/article/14647-eng.pdf?st=OGqiQ-qC.

[35] Sigurdson E, Staley D, Matas M, Hildahl K, Squair K. A fiveyear review of youth suicide in Manitoba. Canadian Journal of Psychiatry. 1994; 39(8): 397-403.

[36] Malchy, B, Enns, MW, Young KT, Cox BJ. Suicide among Manitoba's Aboriginal people, 1988-1994. Canadian Medical Association Journal. 1997; 156(8): 1133-1138.

[37] Peters T, Goossen R, Chipperfield S, Cooper M, Alix-Roussin A, Brown AM, Clarke D, Fogg B, Pageau B, Zhang L. Manitoba adult suicide mortality review: Risk factors associated with mental health and substance abuse disorders. Winnipeg Regional Health Authority, 2009.

[38] Assembly of First Nations, First Nations registration (status) and membership research report. Ottawa: Ontario, Canada, 2008.

[39] Health Canada. Denominator guidelines for health surveillance in First Nations populations in Canad. Ottawa: Her Majesty the Queen in Right of Canada, represented by the Minister of Health Canada, 2011.

[40] Statistics Canada. Canadian Community Health Survey - Annual Component (CCHS). 2018. Cited on 2018 October 15, 2018. Accessed from http//www.23.statcan.gc.ca/imdb/p2SV. pl?Function $=$ getSurvey $\&$ SDDS $=3226$

[41] Statistics Canada. Aboriginal Peoples Survey (APS). Cited on 2018 October 15. Accessed from https//www.statcan.gc.ca/ eng/survey/household/3250.

[42] Kumer MP. Lifetime suicidal thoughts among First Nations living off reserve, Métis and Inuit aged 26 to 59 : Prevalence and associated characteristics. Ottawa: Statistics Canada; 2016. Cited on 2018 September 16. Accessed from https//www.150.statcan.gc.ca/n1/en/pub/89-653x/89-653-x2016008-eng.pdf?st=AzBYD5qE.

[43] First Nations Information Governance Centre. First Nations Regional Longitudinal Health Survey (RHS) 2002/03: Results for Adults, Youth and Children Living in First Nations Communities. Ottawa: First Nations Information Governance Centre; 2005. Cited on 2018 August 25. Accessed from http//First: Nationsigc.ca/sites/default/files/ENpdf/RHS_ 2002/rhs2002-03-technical_report.pdf.

[44] Elias B, Hart L, Martens PJ. "Just get on with it". Linking data systems to report on infant mortality and the First Nations population in Manitoba (Canada). Statistical Journal of the International Association of Official Statistics. 2014; 30(3): 285-295.

[45] Jebamani LS, Burchill CA, Martens PJ. Using Data Linkage to Identify First Nations Manitobans: Technical, ethical and political issues. Canadian Journal of Public Health. 2005; 96(1): S23-S32.

[46] Martens PJ, Fransoo R, McKeen N, The Need to Know Team, Burland E, Jebamani L, Burchill C, De Coster C, Ekuma O, Prior H, Chateau D, Robinson R, Metge C. Patterns of Re- gional Mental Illness Disorder Diagnoses and Service Use in Manitoba: A Population-Based Study. Winnipeg, MB: Manitoba Centre for Health Policy, 2004.

[47] Langhinrichsen-Rohling J, Friend J, Powell A. Adolescent suicide, gender, and culture: A rate and risk factor analysis. Aggression and Violent Behavior. 2009; 14: 402-414.

[48] Centers for Disease Control and Prevention (CDCa). Suicides among American Indian/Alaska Natives - National Violent Death Reporting System, 18 States, 2003-2014. Morbidity and Mortality Weekly Report. 2018; 67(8): 237-242.

[49] Centers for Disease Control and Prevention (CDCb). Suicide among adults aged 35-64 years - United States, 1999-2010. Morbidity and Mortality Weekly Report. 2013; 62(17): 321325.

[50] Bohn D. Lifetime Physical and Sexual Abuse, Substance Abuse, Depression, and Suicide Attempts Among Native American Women. Issues of Mental Health Nursing. 2003; 24(3): 333-352.

[51] Elias B, Mignone J, Hall M, Hong SP, Hart L, Sareen J. Trauma and suicide behaviour histories among a Canadian Indigenous population: An empirical exploration of the potential role of Canada's residential school system. Social Science and Medicine. 2012; 74; 1560-1569.

[52] Mann J, Apter A, Bertolote J, et al. Suicide Prevention Strategies: A Systematic Review. The Journal of the American Medical Association. 2005; 294(16): 2064-2074.

[53] Goldney RD. Suicide prevention. Oxford University Press, 2008.

[54] Yip PSF, Caine E, Yousuf S, Chang S, Chien-Chang WK, Chen Y. Means restriction for suicide prevention. Lancet. 2012; 369: 2393-2399.

[55] Kirmayer LJ. Changing patterns in suicide among young people. Canadian Medical Association Journal. 2012; 184(9): 1015-1016.

[56] Skinner R, McFaull S. Suicide among children and adolescents in Canada: trends and sex differences 1980-2008. Canadian Medical Association Journal. 2012; 184(9): 1029-34.

[57] Skinner R, McFaull S, Rhodes AE, Bowes M, Rockett IRH. Suicide in Canada: Is poisoning misclassification an issue. The Canadian Journal of Psychiatry. 2016; 61(7): 405-412.

[58] Donaldson AE, Larsen GY, Fullerton-Gleason L, Olson LM, Classifying undetermined poisoning deaths. Injury Prevention. 2006; 12(5): 338-342.

[59] Gunnell D, Frankel S. Prevention of suicide: aspirations and evidence. British Medical Journal. 1994; 308(6938): $1227-$ 1233.

[60] De Leo D. Struggling against suicide: the need for an integrative approach. Crisis. 2002; 23(1): 23-31.

[61] Goldney RD, Fisher LJ. Have broad-based community and professional education programs influenced mental health literacy and treatment seeking of those with major depression and suicidal ideation? Suicide and Life-Threatening Behavior. 2008; 38(2): 129-142.

[62] World Health Organization. Towards evidence-based suicide prevention programmes. Geneva, Switzerland; 2010. Cited on 2018 May 8. Accessed from http//iris.wpro.who.int/bitstream/ handle/10665.1/5497/9789290614623_eng.pdf.

[63] Mota N, Elias B, Tefft B, Medved M, Munro G, Sareen J, the Swampy Cree Suicide Prevention Team. Correlates of suicidality: investigation of a representative sample of Manitoba First Nations Adolescents. American Journal of Public Health. 2011; 102(7): 1353-61.

[64] Bombay A, Matheson K, Anisman H. The intergenerational effects of Indian Residential Schools: Implications for the 
concept of historical trauma. Transcultural Psychiatry. 2014; 51(3): 320-338.

[65] McQuaid RJ, Bombay A, McInnis OA, Humeny C, Matheson K, Anisman H. Suicide Ideation and Attempts among First Nations Peoples Living On-Reserve in Canada: The Intergenerational and Cumulative Effects of Indian Residential Schools. The Canadian Journal of Psychiatry. 2017; 62(6): 422-430.

[66] Evans-Campbell T, Walters KL, Pearson CR, Campbell CD. Indian boarding school experience, substance use, and mental health among urban two-spirt American Indian/Alaska natives. American Journal of Drug and Alcohol Use. 2012; 38(5): 421-427.

[67] Hunter E, Milroy H. Aboriginal and Torres Strait Islander Suicide in Contact. Archives of Suicide Research. 2006; 10(2): 141-157.

[68] Wolitzky-Taylor KB, Ruggiero KJ, McCart MR et al., Has adolescent suicidality decreased in the United States? Dat from two national samples of adolescents interviewed in 1995 and 2005. J Clin Child Adolesc Psychol. 2010; 39(1): 64-76.

[69] Waldrop AE, Hanson RF, Resnick HS, Kilpatrick DG, Naugle AE, Saunders BE. Risk factors for suicidal behavior among a national sample of adolescents: implications for prevention. J Trauma Stress. 2007; 20(5): 869-879.

[70] Koplin B, Agathen J. Suicidality in children and adolescents: a review. Curr Opin Pediatr. 2002; 14(6): 713-717.

[71] Maimon D, Browning CR, Brooks-Gunn J. Collective efficacy, family attachment, and urban adolescent suicide attempts. J Health Soc Behav. 2010; 51(3): 307-324.

[72] First Nations Centre. First Nations Regional Longitudinal Health Survey (RHS) 2002/03: Results for adults, youth, and children living in First Nations communities. Ottawa, Canada: First Nations Centre, 2005.

[73] Chandler MJ, Lalonde CE. Cultural continuity as a protective factor against suicide in First Nations youth. Horizons: A Special Issue on Aboriginal Youth, Hope or Heartbreak. 2008; 10(1): 68-72.

[74] Auger MD (2016). Cultural Continuity as a Determinant of Indigenous Peoples' Health: A Metasynthesis of Qualitative Research in Canada and the United States. The International Indigenous Policy Journal. 2010; 7(4). doi 10.18584/iipj.2016.7.4.3. Accessed from http//ir.lib.uwo.ca/ iipj/vol7/iss $4 / 3$.
[75] Hatcher S, Crawford A, Coupe N. Preventing suicide in Indigenous communities. Current Opinion in Psychiatry. 2017; 30(1): 21-25.

[76] Clifford AC, Doran CM, Tsey K. A systematic review of suicide prevention interventions targeting indigenous peoples in Australia, United States, Canada and New Zealand. BMC Public Health. 2013; 13: 463. https//doi.org/10.1186/14712458-13-463.

[77] Hatcher S, Coupe N, Wikiriwhi K, Durie SM, Pillai A. Te Ira Tangata: a Zelen randomised controlled trial of a culturally informed treatment compared with treatment as usual in Māori who present to hospital after self-harm. Soc Psychiatry Psychiatr Epidemiol. 2016; 51(6): 885-94.

[78] Sareen J, Isaak C, Bolton SL, Enns MW, Elias B, Deane F, Munro G, Stein MB, Chateau D, Gould M, Katz LY. Gatekeeper training for suicide prevention in First Nations community members: A randomized controlled trial. Depression and Anxiety. 2013; 30(10): 1021-1029.

[79] Brownell M, Enns JE, Hanlon-Dearman, A, Chateau D, Phillips-Beck W, Singal D, MacWilliam L, Longstaffe S, Chudley A, Elias B, Roos N. Health, Social and Justice Outcomes among Manitoba First Nations Children Diagnosed with Fetal Alcohol Spectrum Disorder: A Population-Based Cohort Study of Linked Administrative Data. The Canadian Journal of Psychiatry. In Press December 17, 2018.

[80] Liu RT, Trout ZM, Hernandez EM, Cheek SM, Gerlus N. A behavioral and cognitive neuroscience perspective on impulsivity, suicide, and non-suicidal self-injury: Meta-analysis and recommendations for future research. Neuroscience \& Behavioral Reviews 2017; 83: 440-450.

[81] Minsky A. In their words: What residential school survivors told the Truth and Conciliation Commission. Global News June 2; 2015. Cited 2018 October 4. Accessed from https//glo balnews.ca/news/2031617/in-their-words-what-residentialschool-survivors-told-the-truth-and-reconciliation-commiss ion/ on September 82018. 


\section{Supplementary data}
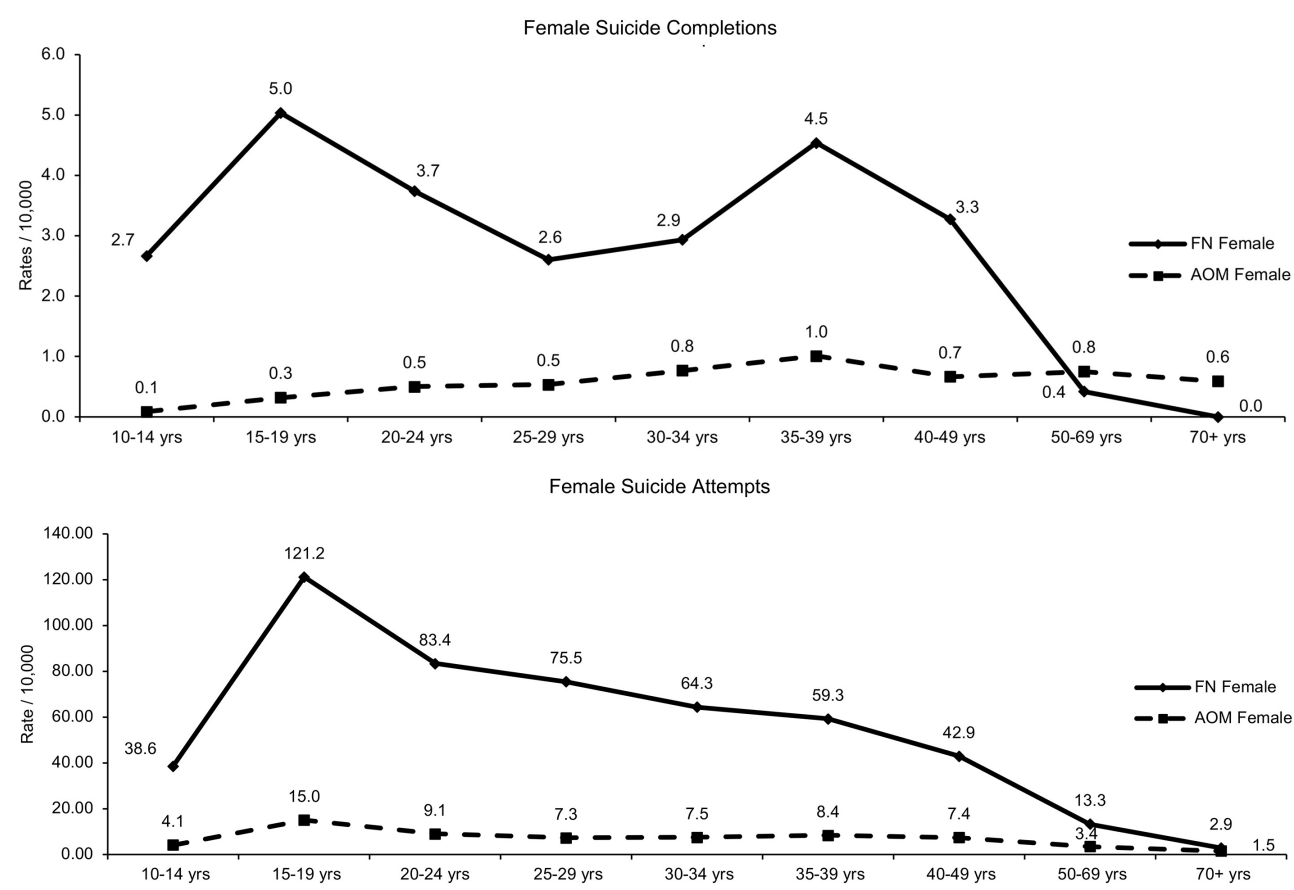

Supplement Fig. 1. Age-specific rate for females, suicide completions and suicide attempts, per 10,000 residents age 10+ comparing First Nations (FN) and All Other Manitobans (AOM) for the period 1997-2006 in the Province of Manitoba (vital statistics data, physician data, hospital data).
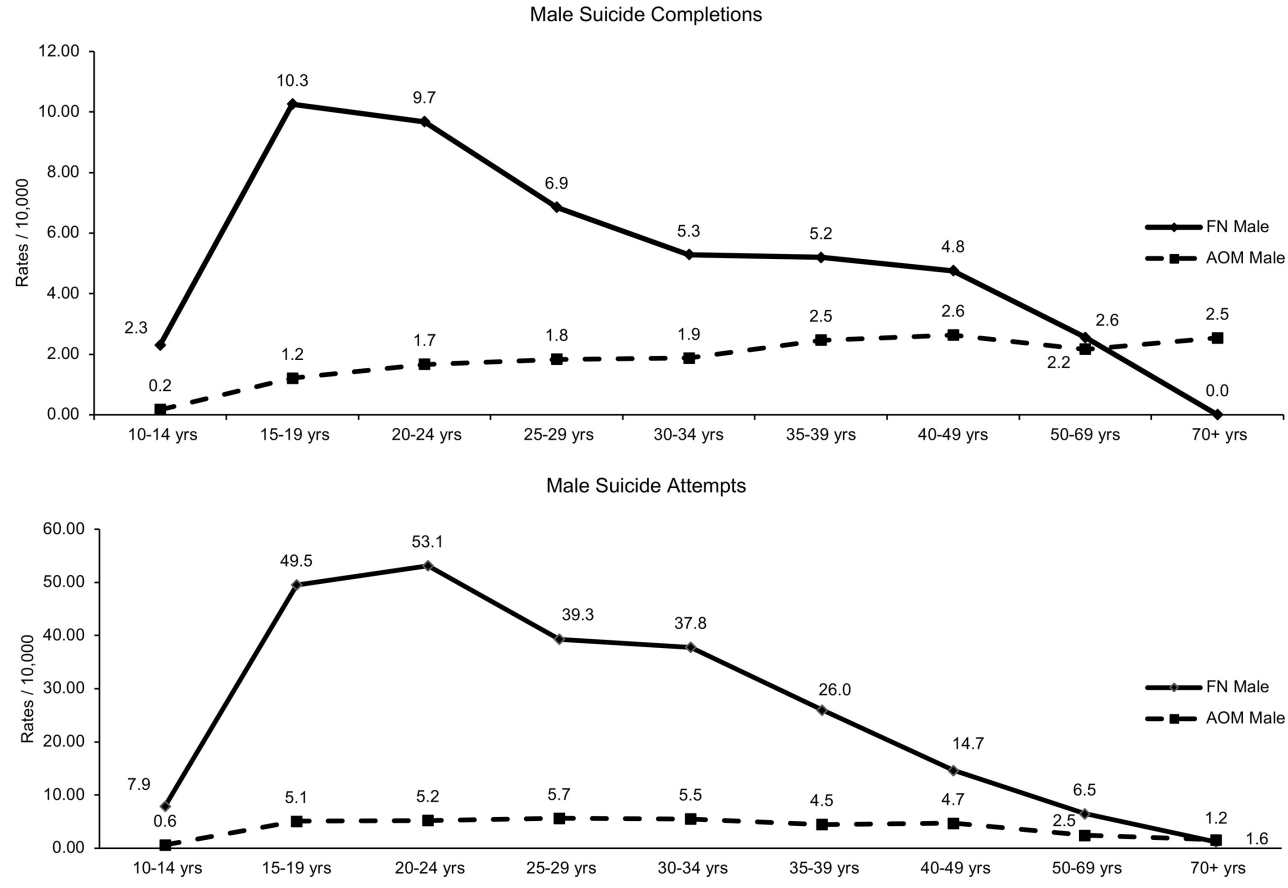

Supplement Fig. 2. Age-specific rate for males, suicide completions and suicide attempts per 10,000 residents age 10+ comparing First Nations (FN) and All Other Manitobans (AOM) for the period 1997-2006 in the Province of Manitoba (vital statistics data, physician data, hospital data). 